\title{
Low awareness but positive attitudes toward fecal transplantation in Ontario physicians
}

\author{
Madison Dennis MD ${ }^{1}$, Mary Jane Salpeter RN BHA ${ }^{2}$, Susy Hota MSc MD ${ }^{1,2,3}$
}

M Dennis, MJ Salpeter, S Hota. Low awareness but positive attitudes toward fecal transplantation in Ontario physicians. Can J Infect Dis Med Microbiol 2015;26(1):30-32.

BACKGROUND: Despite mounting evidence supporting fecal transplantation (FT) as a treatment for recurrent Clostridium difficile infection (CDI), adoption into clinical practice has been slow.

OBJECTIVE: To determine the health literacy and attitudes of academic physicians in Toronto and infectious disease physicians in Ontario toward FT as a treatment for recurrent CDI, and to determine whether these are significant barriers to adoption.

METHODS: Surveys were distributed to 253 general internists, infectious diseases specialists, gastroenterologists and family physicians.

RESULTS: The response rate was $15 \%$. More than $60 \%$ of physicians described themselves as being 'not at all' or 'somewhat' familiar with FT. Of the $76 \%$ of physicians who had never referred a patient for FT, the most common reason (50\%) was lack of awareness of where to access the treatment. The 'ick factor' accounted for only $13 \%$ of reasons for not referring. No respondent believed that the procedure was too risky to consider.

CONCLUSION: Despite general poor health literacy on FT, most physicians sampled share similar positive attitudes toward the treatment.

Key Words: Fecal transplantation; Physician attitudes; Physician health literacy; Recurrent Clostridium difficile infection

\section{La transplantation fécale peu connue, mais accueillie positivement par les médecins ontariens}

HISTORIQUE : Malgré les données croissantes en appui à la transplantation fécale (TF) pour traiter l'infection à Clostridium difficile (ICD) récurrente, son adoption est lente en pratique clinique.

OBJECTIF : Déterminer les connaissances et les attitudes des médecins universitaires de Toronto et des infectiologues de l'Ontario envers la TF pour traiter l'ICD récurrente et déterminer si elles constituent d'importants obstacles à leur adoption.

MÉTHODOLOGIE : Des sondages ont été distribués à 253 internistes généraux, infectiologues, gastroentérologues et médecins de famille.

RÉSULTATS : Le taux de réponse s'élevait à $15 \%$. Plus de $60 \%$ des médecins se décrivaient comme "pas du tout » ou «quelque peu » familiers avec la TF. Des $76 \%$ de médecins qui n'avaient jamais orienté un patient vers une TF, $50 \%$ affirmaient manquer de connaissance quant à l'accès au traitement. Le facteur " peu ragoûtant » ne constituait que $13 \%$ des raisons de ne pas aiguiller les patients. Aucun répondant ne trouvait l'intervention trop risquée pour être envisagée.

CONCLUSION : Malgré le peu de connaissances générales sur la TF, la plupart des médecins interrogés avaient les mêmes attitudes positives envers le traitement.
$\mathrm{R}$ ecurrent Clostridium difficile infection (RCDI) is associated with high morbidity and mortality (1). Current standard treatments leave $30 \%$ of patients with further recurrences (2). One alternative therapy is fecal transplantation (FT), in which stool from a healthy, screened donor is administered to the recipient by nasojejunal tube, enema or colonoscopy. Several case reports and series have demonstrated promising results for FT as a treatment for RCDI (3). A recent systematic review of 317 patients involved in 27 case series found a success rate of $92 \%$ for FT with no adverse events (4). A randomized controlled trial also demonstrated that FT initially cured $81 \%$ of patients; $94 \%$ of patients were cured after repeat infusion, and no significant adverse events were observed (5).

Despite this, FT is still not commonly used. Many articles list the inherently unappealing nature of FT - the 'ick factor' - as a reason why patients would be opposed to it, but they provide no evidence for this claim $(6,7)$. One survey examining patient attitudes toward FT reported that while patients found the treatment unappealing, $>81 \%$ were open to it; when recommended by their physicians, this number increased to $94 \%$ (8).
In Canada, several hospitals have not supported FT. It has been proposed that it is health care personnel, not patients, who object to FT $(9,10)$. It has even been suggested that physicians' negative attitudes act as a main barrier to FT adoption (11). One brief questionnaire study investigating physician attitudes found that $86 \%$ of physicians would refer patients to a FT centre (12). The present study aims to better understand physician referral patterns, health literacy and attitudes toward FT in Ontario, clarifying barriers to adopting the procedure more widely.

\section{METHODS}

The present study was performed in Ontario between February and April 2011. An electronic survey was created using SurveyMonkey. An introduction and link to the survey was sent via e-mail, using current listservs from the University of Toronto (Toronto, Ontario) department heads and the Ontario Medical Association, to 120 general internists at the University of Toronto, 78 infectious disease specialists at the Ontario Medical Association, and 31 gastroenterologists and 24 family physicians at three academic hospitals in Toronto, Ontario. One reminder e-mail was sent.

\footnotetext{
${ }^{1}$ Faculty of Medicine, University of Toronto; ${ }^{2}$ Department of Infection Prevention and Control, University Health Network; ${ }^{3}$ Division of Infectious Diseases, Department of Medicine, University of Toronto, Toronto, Ontario

Correspondence: Dr Susy Hota, Infection Prevention and Control, Toronto General Hospital, 9th floor Munk Wing, Room 800, 200 Elizabeth Street, Toronto, Ontario M5G 2C4. Telephone 416-340-4800 ext 7287, fax 416-340-5047, e-mail susy.hota@uhn.on.ca
} 


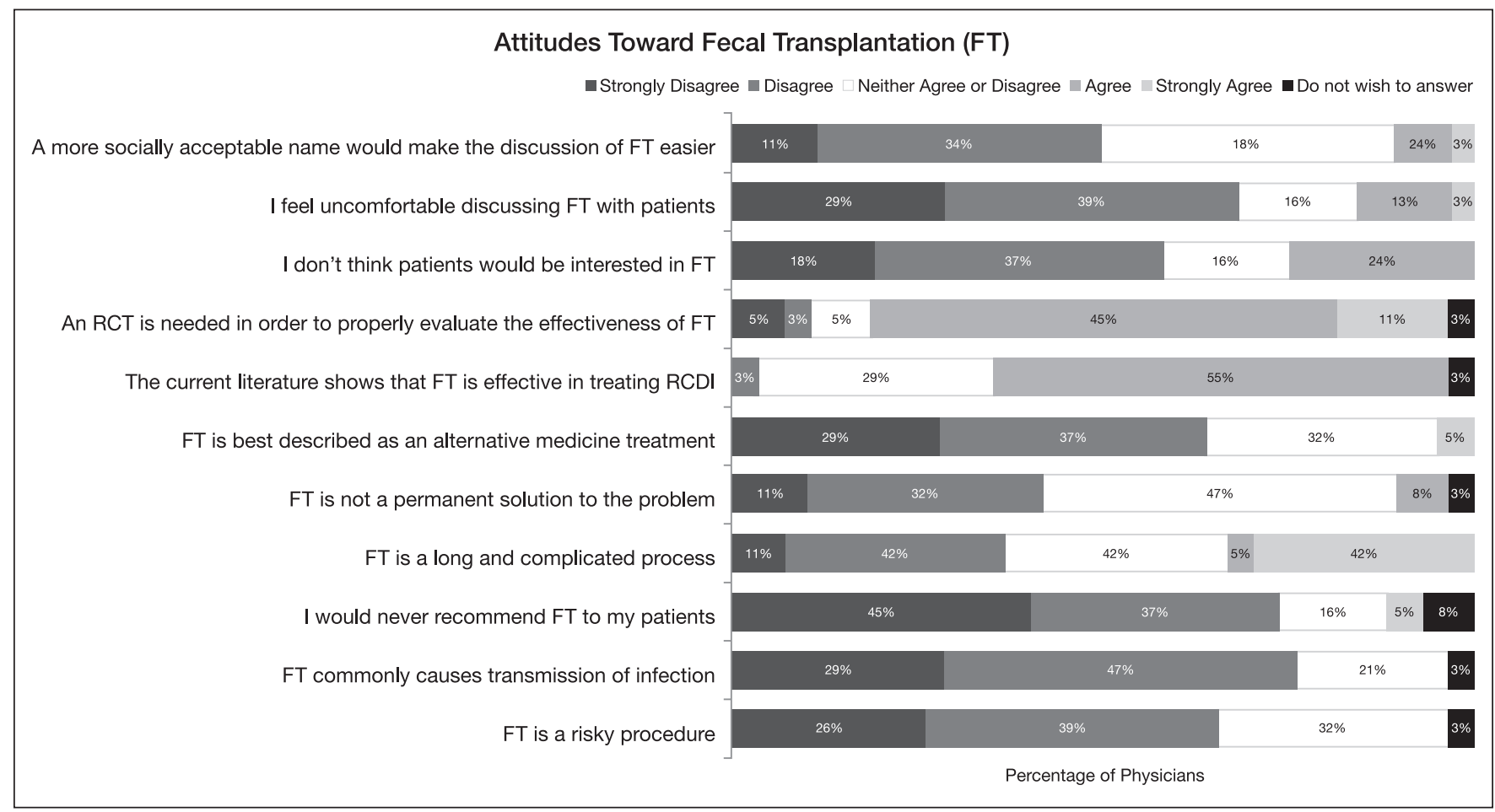

Figure 1) Attitudes toward fecal transplantation. RCDI Recurrent Clostridium difficile infection; RCT Randomized controlled trial

The survey contained five domains: demographic information; past experience with RCDI; knowledge regarding FT; attitudes toward FT; and exploring ways to improve understanding of FT. Multiple-choice responses were used to evaluate knowledge, and attitudes were assessed using a series of Likert-style questions and one open-ended question. The questionnaire was pilot tested and modified for readability, interpretability and face validity. Institutional research ethics board approval was obtained. Standard descriptive statistics were used to analyze the data from the survey. Open-ended questions were qualitatively analyzed for recurring themes.

\section{RESULTS}

Of the 253 surveys disseminated, 39 (15\%) physicians completed the survey: four (17\%) family physicians; 23 (19\%) general internists; three $(10 \%)$ gastroenterologists; and nine $(12 \%)$ infectious disease specialists. The majority of survey participants were male (67\%), general internists $(59 \%)$ and practicing in Toronto $(82 \%)$ at academic centres $(87 \%)$.

In the past five years, $82 \%$ of respondents saw $>20$ cases of $\mathrm{C}$ difficile infection and $36 \%$ saw $>10$ cases of RCDI. Eighteen percent of surveyed physicians had referred patients for FT.

Physicians surveyed first heard about FT from their colleagues (34\%) and from the medical literature (29\%). When asked to report their own health literacy by selecting from 'not at all familiar', 'somewhat familiar', 'fairly familiar' and 'very familiar', $>60 \%$ of physicians described themselves as being not at all or somewhat familiar with FT.

There was no clear consensus on when to use FT. Five percent of surveyed physicians believed that FT should be first-line therapy; 11\% believed it should be used after the first recurrence; $47 \%$ after the second recurrence; $8 \%$ after the third recurrence; and $26 \%$ only as a last resort. Interestingly, no physician believed that FT should never be used.

Respondents were asked to select reasons for not referring for FT. Of the $76 \%$ of physicians who have never referred, the most common reason $(50 \%)$ was they were unaware of where to access the treatment. Other frequently cited reasons were: that physicians believed they did not know enough about the treatment (20\%); the 'ick factor' $(13 \%)$; and the procedure was not supported by their hospital (13\%). Only a small number of physicians did not refer because they assumed the patient was not open to the treatment $(7 \%)$ or because there was not enough scientific evidence (3\%). No physician chose not to refer because the treatment was too risky.

Figure 1 presents the results of surveyed physician attitudes toward FT. Most physicians agreed with the statements: "The current literature shows that FT is effective in treating RCDI" and "A randomized controlled trial (RCT) is needed to properly evaluate the effectiveness of FT". Notably, the survey was conducted before publication of an RCT on FT. There was less agreement regarding the discomfort around FT.

The final question was open ended and asked how to improve physician knowledge and understanding of FT. The main themes were that the surveyed physicians were interested in receiving information and wanted key articles to be sent electronically.

\section{DISCUSSION}

The present survey was the first to study Ontario physician attitudes toward FT as a treatment for RCDI. Our findings suggest that the majority of Ontario physicians surveyed who see patients with RCDI have positive attitudes toward FT, and the main barrier to referral is a lack of health literacy.

Physician health literacy was self-reported to be quite low, with most surveyed physicians believing they were 'not at all' or 'somewhat' familiar with literature and media articles surrounding FT. Additionally, the top two reasons for not referring patients for FT were that physicians were unaware of where to access the treatment and they believed they lacked knowledge on the treatment.

An unanticipated finding of the study was that, despite general poor health literacy on FT, most surveyed physicians shared similar positive attitudes about the effectiveness and safety of the treatment. No respondent agreed with the statements that FT was a risky procedure or that it commonly caused transmission of infection. Interestingly, these are the two main reasons that hospitals in Canada are rejecting the use of FT (10).

While most surveyed physicians agree that FT is effective and safe, a significant minority of physicians felt uncomfortable discussing FT, did not believe their patients would be interested in it and believed a more socially acceptable name would make the discussion easier. For some 
physicians, these negative attitudes prevented them from referring patients for FT, with 13\% not referring because of the 'ick factor' and 7\% because they assume the patient would not be open to it.

Our findings on physician attitudes are similar to a recently published article investigating physician attitudes toward FT that surveyed physicians in New Hampshire and Texas, USA (13). Their study also found that only a small number of physicians did not refer for FT because of safety concerns (7\%) or lack of efficacy (4\%). However, they found that most physicians did not refer for FT because it was not 'the right clinical situation' (33\%), and logistical and institutional barriers accounted for only $23 \%$ compared with $63 \%$ in our study (physicians not knowing where to access FT and FT not being supported in their hospital). They also found that physicians greatly overestimate the intensity of patient aversion. This may account for our study finding that $24 \%$ of physicians agree that patients would not be interested in FT, despite a patient survey finding that up to $94 \%$ of patients would consider FT.

Our study was limited by a low response rate (15\%). Additional limitations include selection bias; $18 \%$ of surveyed physicians had prescribed FT, indicating that those less familiar with RCDI and FT may not have completed the study. There was also a sampling bias

\section{REFERENCES}

1. Loo VG, Poirier L, Miller MA, et al. A predominantly clonal multi-institutional outbreak of Clostridium difficile-associated diarrhea with high morbidity and mortality. N Engl J Med 2005;353:2442-9.

2. McFarland LV, Elmer GW, Surawicz CM. Breaking the cycle: Treatment strategies for 163 cases of recurrent Clostridium difficile disease. Am J Gastroenterol 2002;97:1769-75.

3. Borody TJ, Warren EF, Leis SM, Surace R, Ashman O, Siarakas S. Bacteriotherapy using fecal flora: Toying with human motions. J Clin Gastroenterol 2004;38:475-84.

4. Gough E, Shaikh H, Manges AR. Systematic review of intestinal microbiota transplantation (fecal bacteriotherapy) for recurrent Clostridium difficile infection. Clin Infect Dis 2011;53:994-1002.

5. Van Nood E, Vrieze A, Nieuwdorp M, et al. Duodenal infusion of donor feces for recurrent Clostridium difficile. N Engl J Med 2013:368:407-15.

6. Kelly CP, LaMont JT. Clostridium difficile - more difficult than ever. N Engl J Med 2008;359:1932-40.

7. McFarland LV. Renewed interest in a difficult disease: Clostridium difficile infections - epidemiology and current treatment strategies. Curr Opin Gastroenterol 2009;25:24-35. because most groups were accessed through academic networks. Finally, the majority of physicians who responded to the survey were from academic institutions in one large city. Although this population provides important insight into the attitudes and referring practices of physicians, it is important to survey more family physicians and physicians from the surrounding communities.

Finally, the present study was conducted before the publication of an RCT on FT for RCDI. It is unclear whether the results of this trial, which was stopped early, have affected physicians' attitudes and health literacy on the subject. The overall landscape of FT has been rapidly changing in terms of the overall published evidence, the regulatory landscape, the rise in at-home FT and increasing media coverage. For these reasons, it would be interesting to repeat our survey to evaluate the impact of all these factors on physician attitudes.

FUNDING: This study was supported by internal funds from the Department of Infection Prevention and Control, University Health Network, Toronto, Ontario.

DISCLOSURE: Susy Hota has served on an advisory board for Cubist Pharmaceuticals.

8. Zipursky JS, Sidorsky TI, Freedman CA, Sidorsky MN, Kirkland KB. Patient attitudes toward the use of fecal microbiota transplantation in the treatment of recurrent Clostridium difficile infection. Clin Infect Dis 2012;55:1652-8.

9. Floch MH. Fecal bacteriotherapy, fecal transplant, and the microbiome. J Clin Gastroenterol 2010;44:529-30.

10. Glauser W. Risk and rewards of fecal transplants. CMAJ 2011;183:541-2.

11. Brandt LJ. Fecal microbiota transplantation: Patient and physician attitudes. Clin Infect Dis 2012;55:1659-60.

12. Jiang ZD, Hoang LN, Lasco TM, Garey KW, Dupont HL. Physician attitudes toward the use of fecal transplantation for recurrent Clostridium difficile infection in a metropolitan area. Clin Infect Dis 2013;56:1059-60.

13. Zipursky JS, Sidorsky TI, Freedman CA, Sidorsky MN, Kirkland KB. Physician attitudes towards the use of fecal microbiota transplantation for the treatment of recurrent Clostridium difficile infection. Can J Gastroenterol Hepatol 2014;28:319-24. 


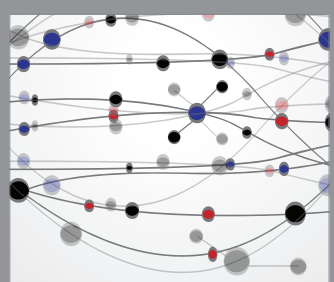

The Scientific World Journal
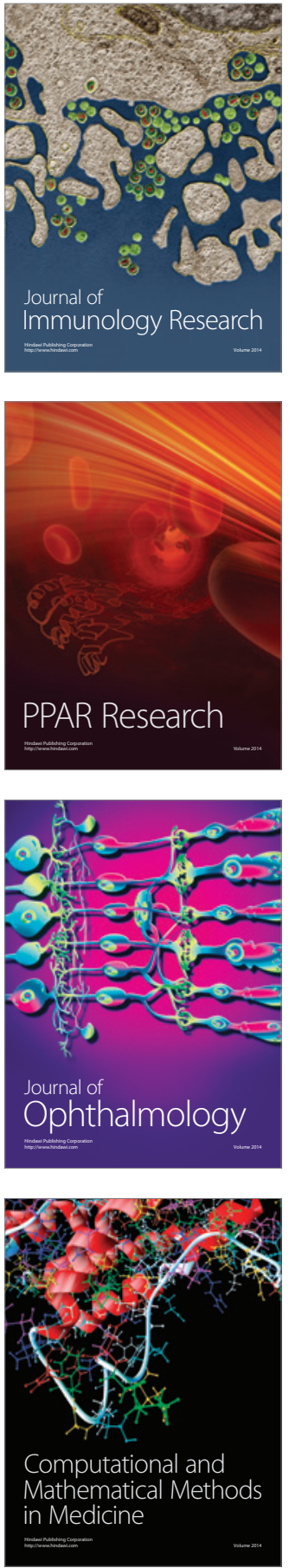

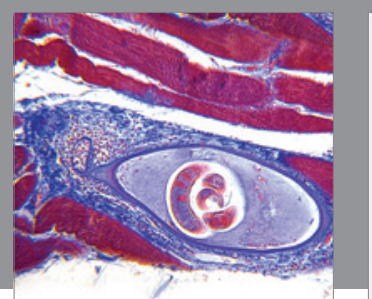

Gastroenterology Research and Practice

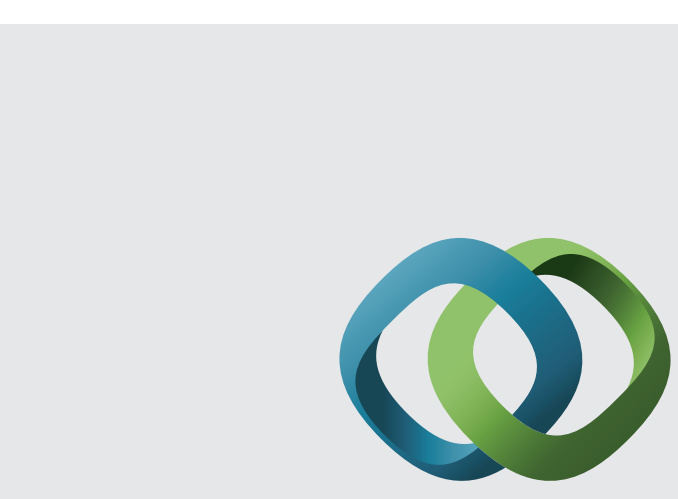

\section{Hindawi}

Submit your manuscripts at

http://www.hindawi.com
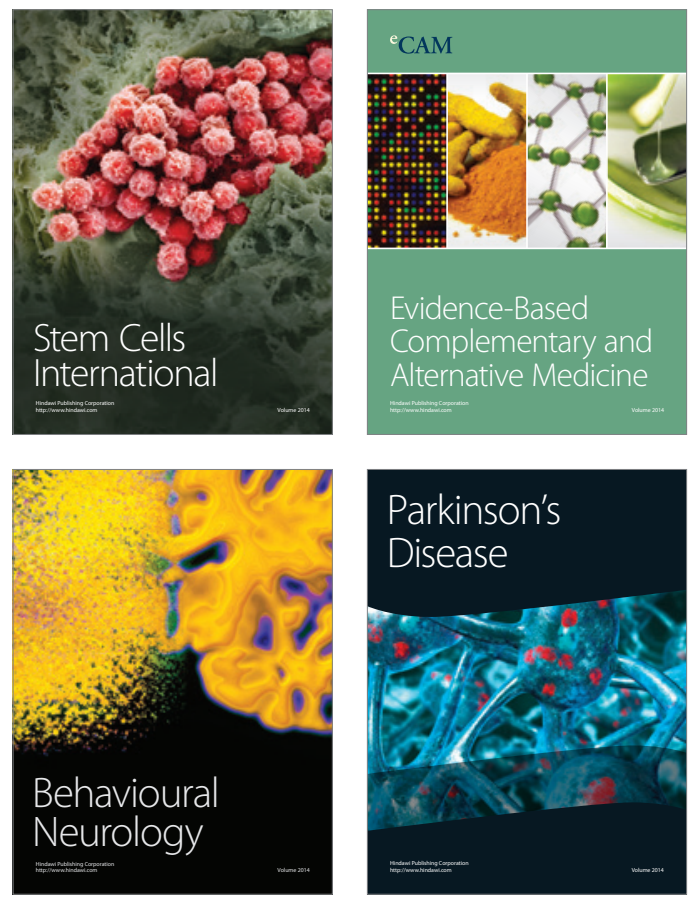
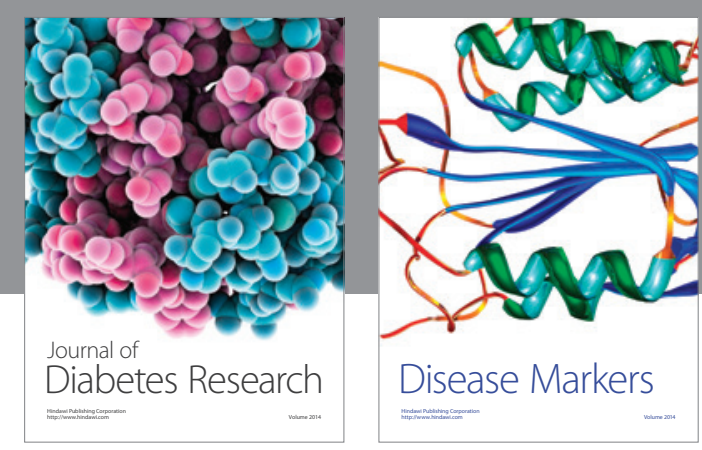

Disease Markers
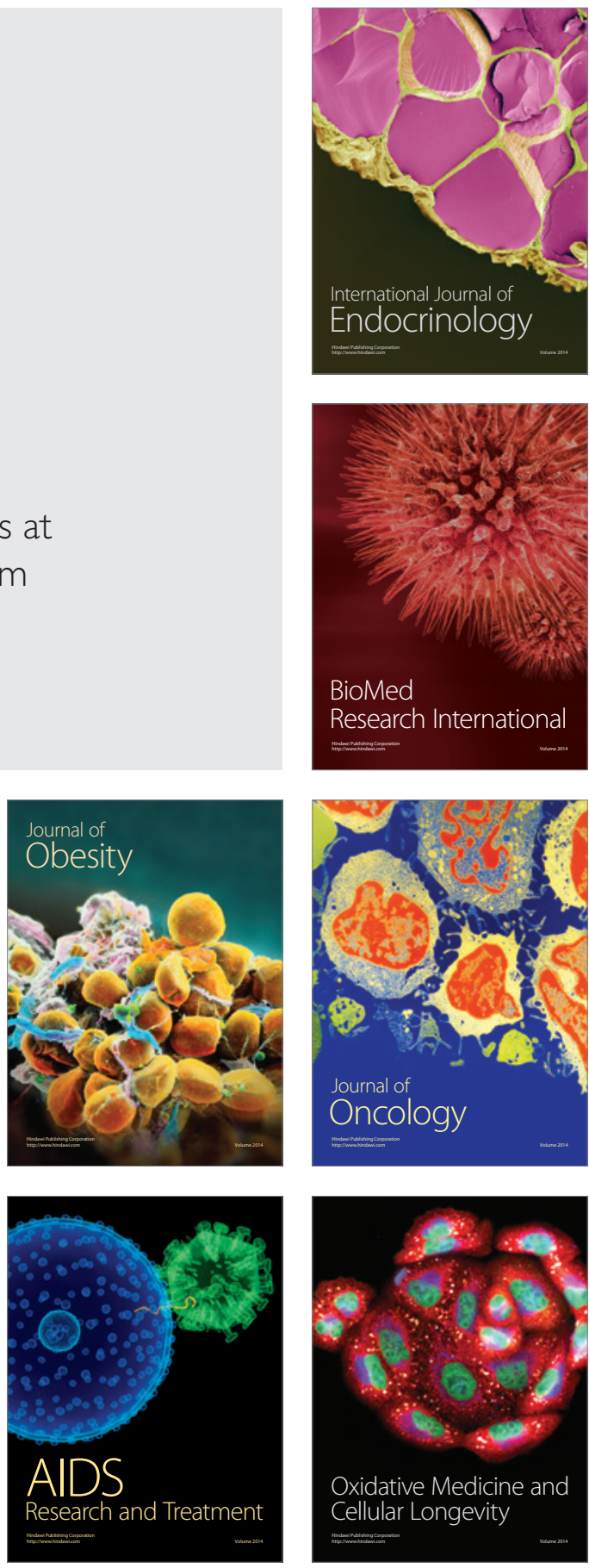